\title{
DEVELOPMENT OF MICROEMULSION AND WATER/OIL/WATER MULTIPLE EMULSION CONTAINING BETA-ARBUTIN, LACTIC ACID, AND SODIUM ASCORBYL PHOSPHATE
}

\author{
SILVIA SURINI*, NUR MPN NEGORO \\ Laboratory of Pharmaceutics and Pharmaceutical Technology Development, Faculty of Pharmacy, Universitas Indonesia, Depok, \\ West Java, Indonesia. Email: silvia@farmasi.ui.ac.id
}

Received: 02 October 2019, Revised and Accepted: 24 December 2019

\section{ABSTRACT}

Objective: In addition to lactic acid and sodium ascorbyl phosphate, which have whitening effects, beta-arbutin is a safe whitening agent for skin. Combining these three substances should reduce the concentration of each one in a formula and achieve an optimal whitening effect. In this study, microemulsions and water/oil/water $(\mathrm{W} / \mathrm{O} / \mathrm{W})$ multiple emulsions were applied to produce a formula containing these whitening agents.

Methods: All the active ingredients were formulated into microemulsions and W/0/W multiple emulsions with different concentrations of Tween 80 and Span 80 as emulsifiers to obtain a stable formula. Twelve-week physical stability studies were performed for every formula at low ( $4 \pm 2^{\circ} \mathrm{C}$ ), room $\left(28 \pm 2^{\circ} \mathrm{C}\right)$, and high $\left(40 \pm 2^{\circ} \mathrm{C}\right)$ temperatures.

Results: The produced microemulsions were transparent with a mean droplet size of $15.50 \mathrm{~nm}$. In addition, the W/O/W multiple emulsions contained droplets within droplets, which were dispersed in a continuous phase with an inner droplet size of $0.15 \mu \mathrm{m}$ and an outer droplet size of $0.37 \mu \mathrm{m}$. The $\mathrm{W} / \mathrm{O} / \mathrm{W}$ multiple emulsions showed pseudoplastic thixotropic flow properties. Furthermore, the microemulsions were stable at low (4 $\left.\pm 2^{\circ} \mathrm{C}\right)$ and room $\left(28 \pm 2^{\circ} \mathrm{C}\right)$ temperatures, while the $\mathrm{W} / \mathrm{O} / \mathrm{W}$ multiple emulsions were stable at room $\left(28 \pm 2^{\circ} \mathrm{C}\right)$ and high $\left(40 \pm 2^{\circ} \mathrm{C}\right)$ temperatures.

Conclusion: It was concluded that the combination of beta-arbutin, lactic acid, and sodium ascorbyl phosphate was suitable for formulating into microemulsions as well as $\mathrm{W} / \mathrm{O} / \mathrm{W}$ multiple emulsions as whitening cosmetic products.

Keywords: Beta-arbutin, Lactic acid, Sodium ascorbyl phosphate, Multiple emulsions, Microemulsions.

(C) 2020 The Authors. Published by Innovare Academic Sciences Pvt Ltd. This is an open access article under the CC BY license (http://creativecommons. org/licenses/by/4. 0/) DOI: http://dx.doi.org/10.22159/ijap.2020.v12s1.FF048

\section{INTRODUCTION}

Many women in tropical countries want to have white skin because this shows that they are beautiful and also having white skin is an essential need $[1,2]$. They have tried many ways of obtaining white skin; thus, whitening cosmetics have become an important commodity [1]. An ideal whitening agent, known as a depigmentation agent, must be potent, fast, and selective to hyperactive melanocyte cells, have minimal short- or long-term side effects, and permanently remove abnormal pigments [3]. Arbutin is a safe depigmentation agent [4]. Besides arbutin, alpha-hydroxy acid (AHA) compounds and derivatives of Vitamin $\mathrm{C}$ also show whitening effects and are considered safe for skin $[5,6]$.

Lactic acid is an AHA compound that exhibits whitening activity. The topical administration of lactic acid can modify the epidermal structure of the skin, and lactic acid acts as an enhanced by increasing the penetration of active ingredients into the skin [7]. Stiller et al. showed that lactic acid also reduces hyperpigmentation [8]. Derivatives of Vitamin $C$ in the ascorbyl form, such as sodium ascorbyl phosphate, prevent skin aging by increasing collagen formation and also exhibit whitening activity because of their role in preventing melanin formation [9]. Combining arbutin, lactic acid, and sodium ascorbyl phosphate are expected to reduce the concentration of each active ingredient, and this combination can be formulated into a stable dosage form to provide an optimum whitening effect. Microemulsions and multiple emulsions are dosage forms with good stability.

Microemulsions are thermodynamically stable and can increase the absorption and penetration of drugs because of their small droplet sizes. Microemulsions can increase the solubility of non-water-soluble drugs, thus increasing their absorption and bioavailability [10]. A study by Peira et al. tested the stability of a microemulsion containing arbutin and kojic acid with perfume toward sun exposure, and the results showed that the microemulsion was more stable than a conventional emulsion [11].

In cosmetic science, multiple emulsions are used because of their ability to extend the release of active substances by incorporating two phases and to protect active substances by dispersing them in the inner phase [12]. A water/oil/water (W/O/W) multiple emulsion is a system in which water droplets are absorbed by larger droplets of the oil phase and dispersed in the continuous water phase. This characteristic can improve the stability of oil-soluble and watersoluble compounds [13].

In this study, two types of dosage forms were produced, a microemulsion and a W/O/W double emulsion, contain a combination of arbutin, lactic acid, and sodium ascorbyl phosphate. Formulas were produced in each dosage form containing three different surfactant concentrations. The overall formulas and their physical stability were tested to obtain the best and most stable formula.

\section{MATERIALS AND METHODS}

\section{Materials}

Beta-arbutin (Asia Visions, Hong Kong), lactic acid (Purac, Thailand), tocotrienol (Davos Life Science, Singapore), sodium ascorbyl phosphate (DSM Nutritional Products, Singapore), Tween 80 (KAO, Japan), Span 80 (KAO, Japan), xanthan gum (VersaGum ${ }^{\mathrm{TM}} 80$, China), sodium chloride (Merck, Germany), propylene glycol, methylparaben, propylparaben, isopropyl myristate (Dow Chemical Pacific, Singapore), ethanol 96\% (Brataco, Indonesia), and butylated hydroxytoluene (SPP Chemical, India) were used. 
Preparation of microemulsions

Microemulsions were produced according to three formulas with Tween 80 concentrations of $20 \%, 22.5 \%$, and $25 \%$, as shown in Table 1 . The microemulsions were formulated by producing the water and oil phases separately. The water phase was divided into three parts. The first was used with xanthan gum to form a gel. The second was added to Tween 80 and then homogenized and heated at approximately $50^{\circ} \mathrm{C}$. The third was used to dissolve the water phase, which contained arbutin, sodium ascorbyl phosphate, and $\mathrm{Na}_{2}$ EDTA. Methylparaben and propylparaben were dissolved in a mixture of lactic acid and propylene glycol, added to the second part of the water phase, and homogenized and heated at approximately $50^{\circ} \mathrm{C}$. The oil phase, which included tocotrienol and butylated hydroxytoluene, was dispersed in isopropyl myristate, homogenized, and heated at the same temperature $\left(50^{\circ} \mathrm{C}\right)$. Ethanol was added to the water phase, and the oil phase was homogenized, added to the water phase, and emulsified with a homogenizer at high speed (1000 rpm) for $10 \mathrm{~min}$ to form an emulsion. Once the emulsion was formed, xanthan gum that had become gel was added to the emulsion gradually while in the homogenizer $[11,14,15]$.

\section{Preparation of $\mathrm{W} / 0 / \mathrm{W}$ multiple emulsions}

Multiple emulsions were prepared with the same concentrations of betaarbutin, lactic acid, and sodium ascorbyl phosphate, however, various concentrations of Span 80 in oil phase, as shown in Table 2. The method of

Table 1: Formulations of microemulsions containing beta-arbutin, lactic acid, and sodium ascorbyl phosphate

\begin{tabular}{llll}
\hline Materials & \multicolumn{3}{l}{ Microemulsion formulas (\%) } \\
\cline { 2 - 4 } & $\mathbf{A 1}$ & $\mathbf{A 2}$ & $\mathbf{A 3}$ \\
\hline Beta-arbutin & 1 & 1 & 1 \\
Lactic acid & 2 & 2 & 2 \\
Sodium ascorbyl phosphate & 0.15 & 0.15 & 0.15 \\
Tocotrienol & 0.5 & 0.5 & 0.5 \\
Isopropyl myristate & 5 & 5 & 5 \\
Tween 80 & 20 & 22.5 & 25 \\
Ethanol 96\% & 10 & 10 & 10 \\
Propylene glycol & 5 & 5 & 5 \\
Xanthan gum & 0.3 & 0.3 & 0.3 \\
Methylparaben & 0.18 & 0.18 & 0.18 \\
Propylparaben & 0.02 & 0.02 & 0.02 \\
Butylated hydroxytoluene & 0.05 & 0.05 & 0.05 \\
Disodium EDTA & 0.05 & 0.05 & 0.05 \\
Demineralized water & up to 100 & up to 100 & up to 100 \\
\hline
\end{tabular}

Table 2: Formulations of multiple emulsions containing beta-arbutin, lactic acid, and sodium ascorbyl phosphate

\begin{tabular}{llll}
\hline Materials & \multicolumn{2}{l}{$\begin{array}{l}\text { Multiple emulsion } \\
\text { formulas (\%) }\end{array}$} \\
\cline { 2 - 4 } & B1 & B2 & B3 \\
& & & \\
\hline Internal water phase & 1 & 1 & 1 \\
$\quad$ Beta-arbutin & 10 & 10 & 10 \\
Sodium chloride solution 0.2 M & 0.15 & 0.15 & 0.15 \\
Sodium ascorbyl phosphate & & & \\
Oil phase & 0.5 & 0.5 & 0.5 \\
Tocotrienol & 10 & 10 & 10 \\
Isopropyl myristate & 0.1 & 0.1 & 0.1 \\
Butylated hydroxytoluene & 2 & 2.5 & 3 \\
$\quad$ Span 80 & & & \\
External water phase & 5 & 5 & 5 \\
Tween 80 & 2 & 2 & 2 \\
Lactic acid & 5 & 5 & 5 \\
Propylene glycol & 0.7 & 0.7 & 0.7 \\
Xanthan gum & 0.18 & 0.18 & 0.18 \\
Methylparaben & 0.02 & 0.02 & 0.02 \\
Propylparaben & 0.05 & 0.05 & 0.05 \\
Disodium EDTA & up to 100 & up to 100 & up to 100 \\
Sodium chloride solution 0.2 M & & &
\end{tabular}

preparing multiple emulsions was divided into three steps, preparation of an internal water phase, preparation of a W/O first emulsion, and preparation of $\mathrm{W} / \mathrm{O} / \mathrm{W}$ multiple emulsions from the first emulsions. For the first stage, sodium chloride was dissolved in demineralized water to produce a solution, then $\beta$-arbutin and sodium ascorbyl phosphate were homogeneously dissolved in this (internal water phase). The first $\mathrm{W} / \mathrm{O}$ emulsion was then formed by homogeneously mixing tocotrienol, butylated hydroxytoluene butylated hydroxytoluene (BHT), Span 80, and isopropyl myristate. The water phase was added to the oil phase, stirring with a homogenizer (1500 rpm) for $10 \mathrm{~min}$ to form the W/O primary emulsion. The third stage involved preparing a $\mathrm{W} / \mathrm{O} / \mathrm{W}$ multiple emulsion by dividing the outer water phase into three parts. Lactic acid was blended with the first part. Tween 80 was dissolved in one part of the second water phase. These two parts were then mixed and methylparaben and propylparaben, which were previously dissolved in propylene glycol, were added. Xanthan gum was mixed with the third water phase and stirred to form a homogeneous gel mass. The primary emulsion was then added to a solution of the external water phase while stirring using a homogenizer ( $600 \mathrm{rpm}$ ) for $5 \mathrm{~min}$. After emulsification was complete, xanthan gum was added with a slower shearing rate to prevent breakage of the multiple emulsion system $[13,16]$.

\section{Evaluation of the microemulsions and the multiple emulsions}

The microemulsions and multiple emulsions were evaluated by organoleptic and homogeneity testing and by measuring their $\mathrm{pH}$, viscosity, and droplet sizes. Organoleptic observations include color, odor, and homogeneity. The $\mathrm{pH}$ of the formulas was measured using a calibrated $\mathrm{pH}$ meter. Viscosity measurements were performed using a Brookfield viscometer. For microemulsion preparation, oil droplet sizes were measured using a Zetasizer Nano S instrument at weeks 0,8 , and 12. Meanwhile, the multiple emulsion droplet sizes were measured using a particle size analyzer (PSA, LS 100) at weeks 6 and 12. The droplet size was also calculated using the Edmundson formula from biweekly microscopic observations with $\times 1000[13,14,16]$.

\section{Physical stability study}

Physical stability testing was performed using two methods: Storage at different temperatures and cycling tests. For storage at different temperatures, formulas were stored at high $\left(40 \pm 2^{\circ} \mathrm{C}\right)$, room $\left(28 \pm 2^{\circ} \mathrm{C}\right)$, and low $\left(4 \pm 2^{\circ} \mathrm{C}\right)$ temperatures for 12 weeks and then observed biweekly with respect to their organoleptic parameters, homogeneity, and droplet diameter, and their $\mathrm{pH}$ was measured weekly. For cycling tests, formulas were stored at $4^{\circ} \mathrm{C}$ for $24 \mathrm{~h}$ and then at $40^{\circ} \mathrm{C}$ for $24 \mathrm{~h}$. This was one treatment cycle. The experiment was repeated for six cycles. The physical conditions during trial preparation were compared with those of the previous formulas to determine whether syneresis or crystallization occurred. Flow properties were observed after storing the formulas for 4 and 8 weeks at room temperature $[15,17]$.

\section{RESULTS}

\section{Evaluation of microemulsions}

The microemulsions were aqueous liquids that were odorless and homogeneous. The microemulsion with the highest Tween 80 concentration $(25 \%$, formula $\mathrm{A} 3)$ appeared yellower than that with the lowest concentration (20\%, formula A1). The microemulsion with $22.5 \%$ Tween 80 (A2) appeared slightly opaque but clearer than formula $\mathrm{A} 1$. The $\mathrm{pH}$ values of microemulsions $\mathrm{A} 1, \mathrm{~A} 2$, and $\mathrm{A} 3$ at week 0 were $3.03,2.91$, and 3.19 , respectively.

The viscosities of microemulsions A1, A2, and A3 at week 0 were 1130 , 1550, and $1550 \mathrm{cps}$, respectively. Based on viscosity measurements using the Brookfield viscometer, all the formulas have pseudoplastic flow properties, as shown in Fig. 1. The mean droplet sizes of microemulsion formulas A1, A2, and A3 measured with the Malvern Zetasizer Nano $S$ instrument at week 0 were 11.15, 8.46, and $15.50 \mathrm{~nm}$.

\section{Evaluation of $\mathrm{W} / \mathrm{O} / \mathrm{W}$ multiple emulsions}

Organoleptic observations showed that the multiple emulsions had the same physical characteristics and were all white-yellow (Pantone 
PMS 607), odorless, slightly viscous, and homogeneous, with no phase separation. The $\mathrm{pH}$ values of formulas B1 (2\% Span 80$)$, B2 (2.5\% Span 80 ), and B3 (3\% Span 80 ) were 2.6, 2.5, and 2.52, respectively. The viscosities of formulas B1, B2, and B3 at week 0 were 2480, 2720, and 2240 cps, respectively. Based on viscosity measurements, all formulas had pseudoplastic thixotropic flow properties (Fig. 2). The mean droplet diameters of the inner droplets of formulas B1, B2, and B3 were 0.153 , 0.140 , and $0.122 \mu \mathrm{m}$, and the diameters of the outer emulsions were $0.373,0.390$, and $0.304 \mu \mathrm{m}$; moreover, the droplets microphotographs are shown in Fig. 3.
Physical stability of microemulsions

All formulas showed stable and homogeneous organoleptic properties. At low temperature, there was no change in the color of microemulsion formula A1; however, the other two became discolored after 12 weeks. Formula A2 changed from yellow (Pantone PMS 101) to turbid yellow (Pantone PMS 100). Formula A3 changed from clear yellow (Pantone PMS 102) to turbid yellow (Pantone PMS 100).

Changes in the $\mathrm{pH}$ values of the microemulsions after 12 weeks were insignificant. As shown in Fig. 4, the $\mathrm{pH}$ of the three formulas
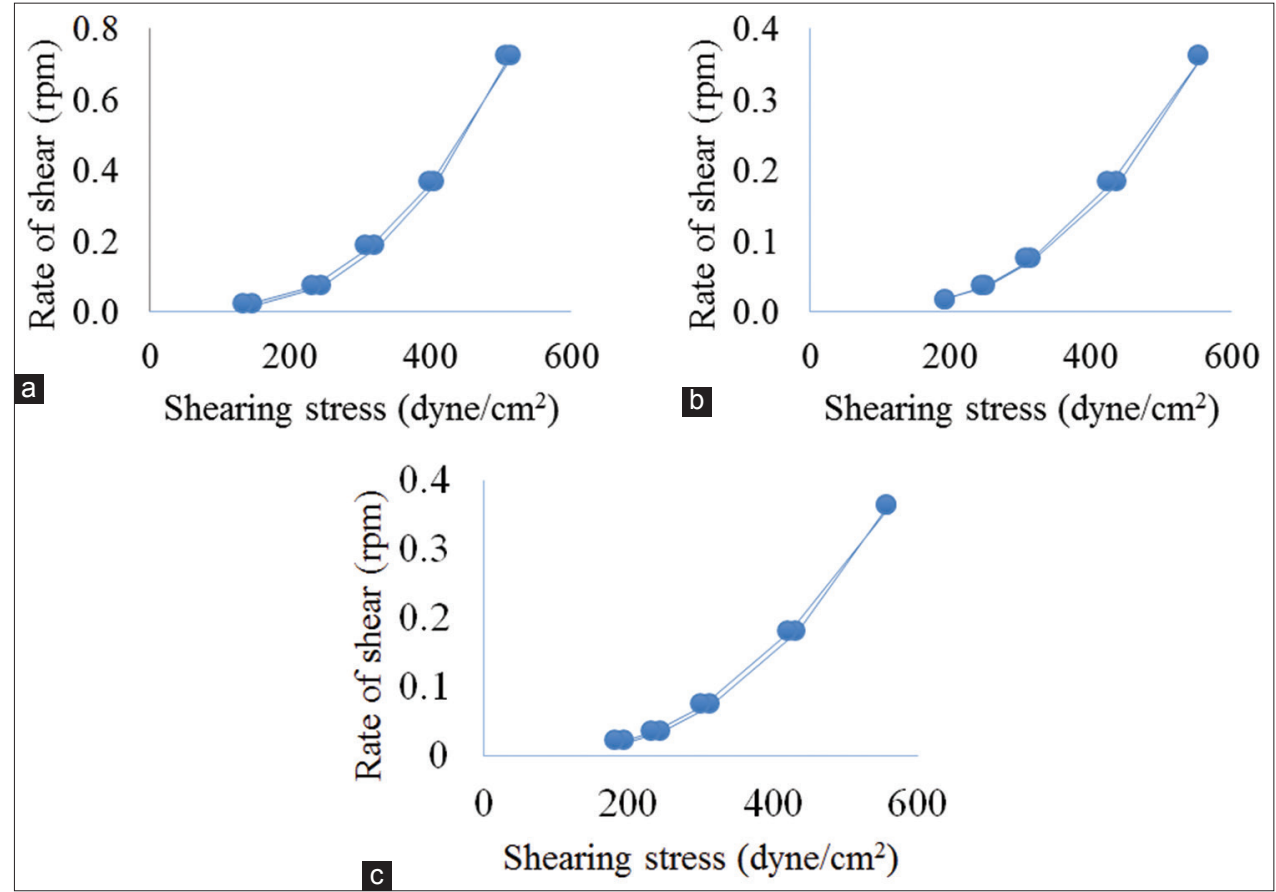

Fig. 1: Rheograms of microemulsion formulas A1 (a), A2 (b), and A3 (c)
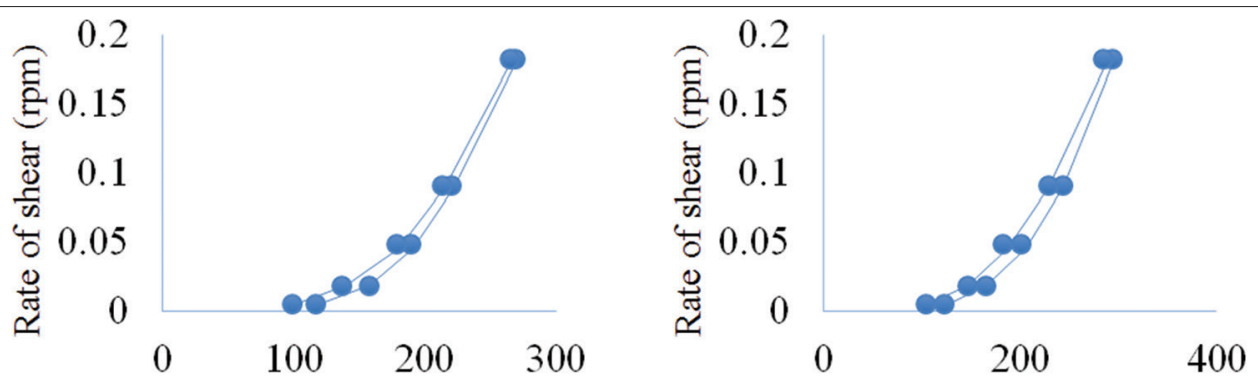

a

Shearing stress $\left(\right.$ dyne $\left./ \mathrm{cm}^{2}\right)$

b

Shearing stress $\left(\right.$ dyne $\left./ \mathrm{cm}^{2}\right)$

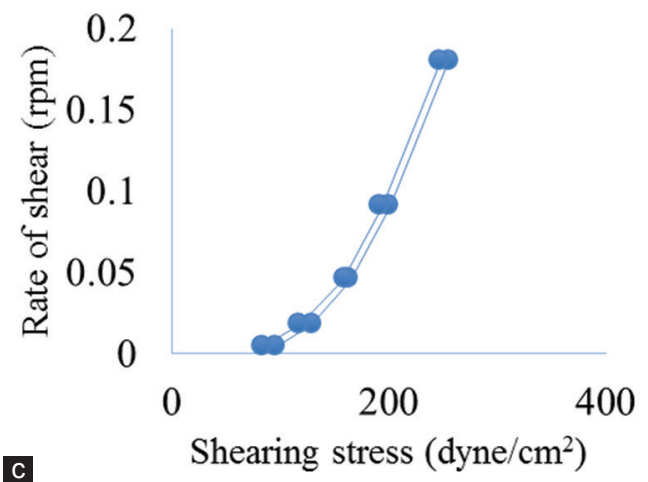

Fig. 2: Rheograms of multiple emulsion formulas B1 (a), B2 (b), and B3 (c) 
Table 3: Mean droplet sizes of microemulsions at weeks 8 and 12

\begin{tabular}{|c|c|c|c|c|c|c|}
\hline \multirow[t]{3}{*}{ Formula } & \multicolumn{6}{|c|}{ Mean droplet size (nm) } \\
\hline & \multicolumn{3}{|c|}{ Week 8} & \multicolumn{3}{|c|}{ Week 12} \\
\hline & $4 \pm 2^{\circ} \mathrm{C}$ & $28 \pm 2^{\circ} \mathrm{C}$ & $40 \pm 2^{\circ} \mathrm{C}$ & $4 \pm 2^{\circ} \mathrm{C}$ & $28 \pm 2^{\circ} \mathrm{C}$ & $40 \pm 2^{\circ} \mathrm{C}$ \\
\hline $\begin{array}{l}\text { A1 }(20 \% \\
\text { Tween } 80)\end{array}$ & 13.28 & 10.34 & 11.30 & 4.34 & 3.09 & 1.25 \\
\hline $\begin{array}{l}\text { A2 (22.5\% } \\
\text { Tween } 80)\end{array}$ & 15.63 & 14.04 & 11.77 & 2.67 & 2.85 & 4.39 \\
\hline $\begin{array}{l}\text { A3 (25\% } \\
\text { Tween } 80)\end{array}$ & 9.75 & 17.65 & 12.49 & 3.68 & 0.67 & 0.57 \\
\hline
\end{tabular}

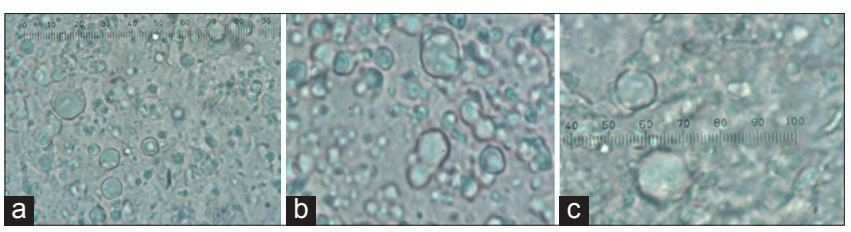

Fig. 3: Microscopic observations of $\mathrm{W} / 0 / \mathrm{W}$ multiple emulsion droplets for formulas B1 (a), B2 (b), and B3 (c) with $\times 1000$ ranges from 2.91 to 3.63 , and the curve shows a relatively stable and insignificant increase in $\mathrm{pH}$.

The mean droplet diameters of the microemulsions of A1, A2, and A3 were measured at weeks 0, 8, and 12, as shown in Fig. 5a-c. Measurements were performed at weeks 8 and 12 on formulas stored at three temperatures, i.e. low, room, and high temperature. The mean droplet sizes of microemulsion formulas A1, A2, and A3 at week 0 were $11.15,8.458$, and $15.50 \mathrm{~nm}$. Measurement results at weeks 8 and 12 are given in Table 3 .

Fig. 6 shows the flow properties of the microemulsions A1, A2, and A3 at weeks 0,4 , and 8 . The viscosities of the microemulsions at week 4 decreased compared with those at week 0 . The viscosities of microemulsion formulas A1, A2, and A3 at week 4 were 1010, 1300, and $1460 \mathrm{cps}$, respectively. The viscosities also decreased from weeks 4 to 8. Formulas A1, A2, and A3 had viscosities of 1000, 1140, and $1430 \mathrm{cps,}$ respectively, with pseudoplastic flow properties.

During cycling test, none of the microemulsion formulas changed color on removal from storage temperatures of $4 \pm 2^{\circ} \mathrm{C}$ or $40 \pm 2^{\circ} \mathrm{C}$. The organoleptic observation indicates that the color of the formulas remained unchanged. Microscopic observations showed that there were no crystals in the microemulsions.

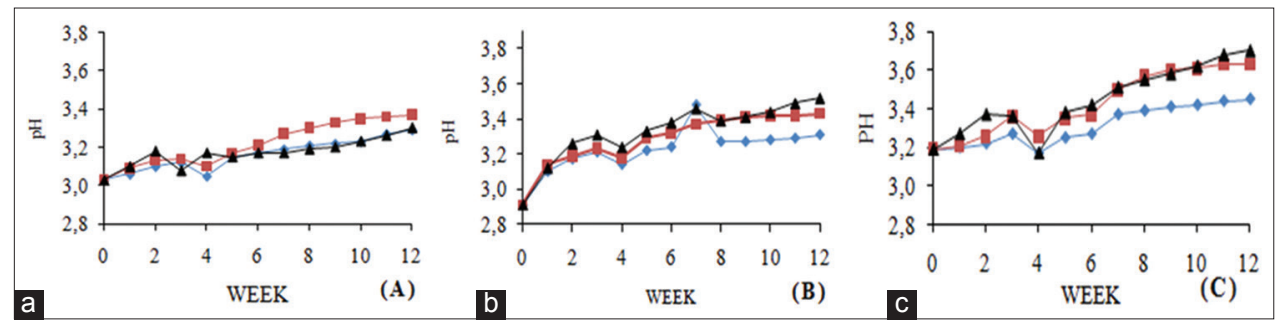

Fig. 4: pH measurements of microemulsion formulas A1 (a), A2 (b), and A3 (c) at low temperature (blue line), room temperature (orange line), and high temperature (black line)

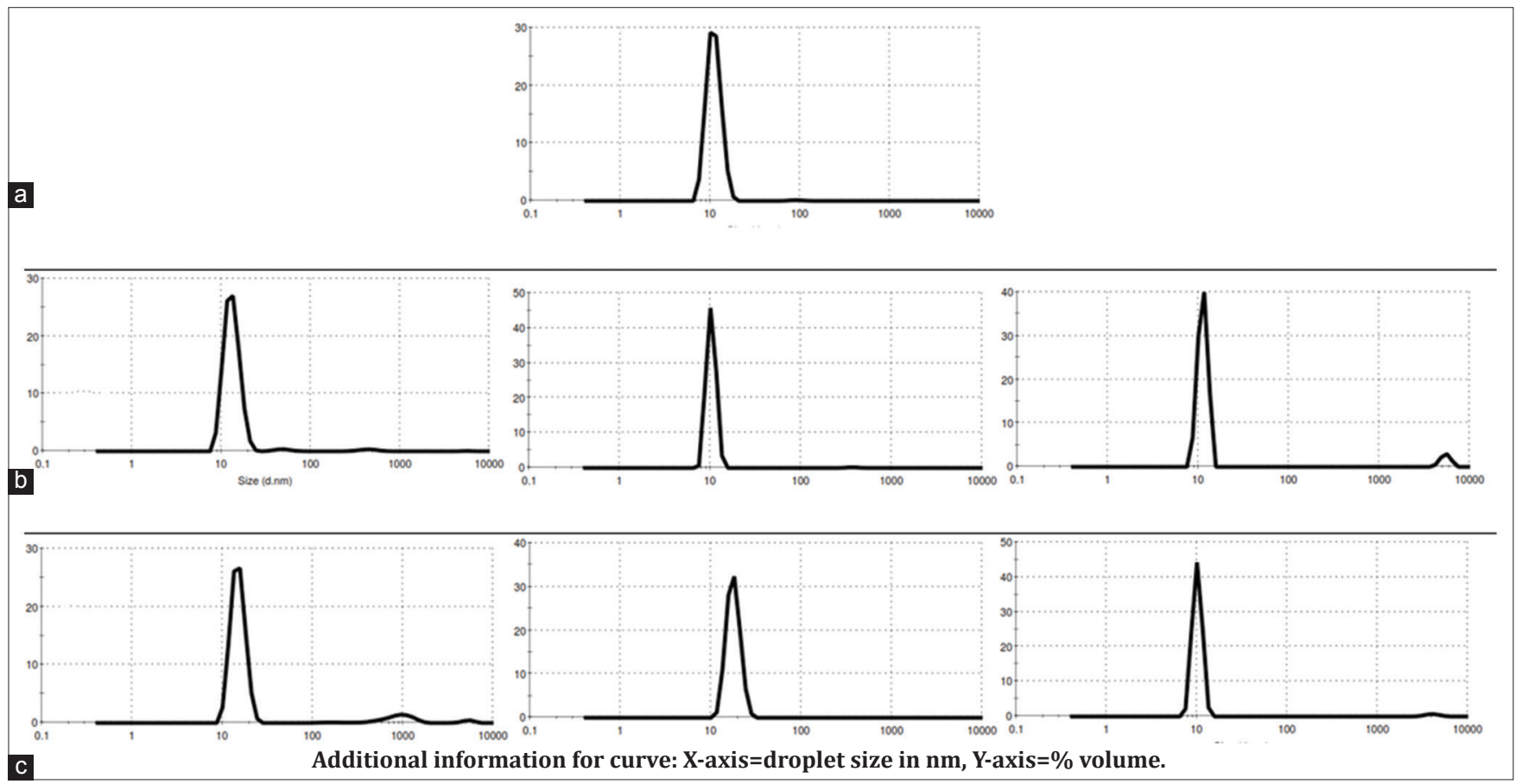

Fig. 5a: Droplet size distribution curves of microemulsion formula A1 (20\% Tween 80 ) stored at low temperature (left), room temperature (middle), and high temperature (right), measured at week 0 (a), week 8 (b), and week 12 (c) 


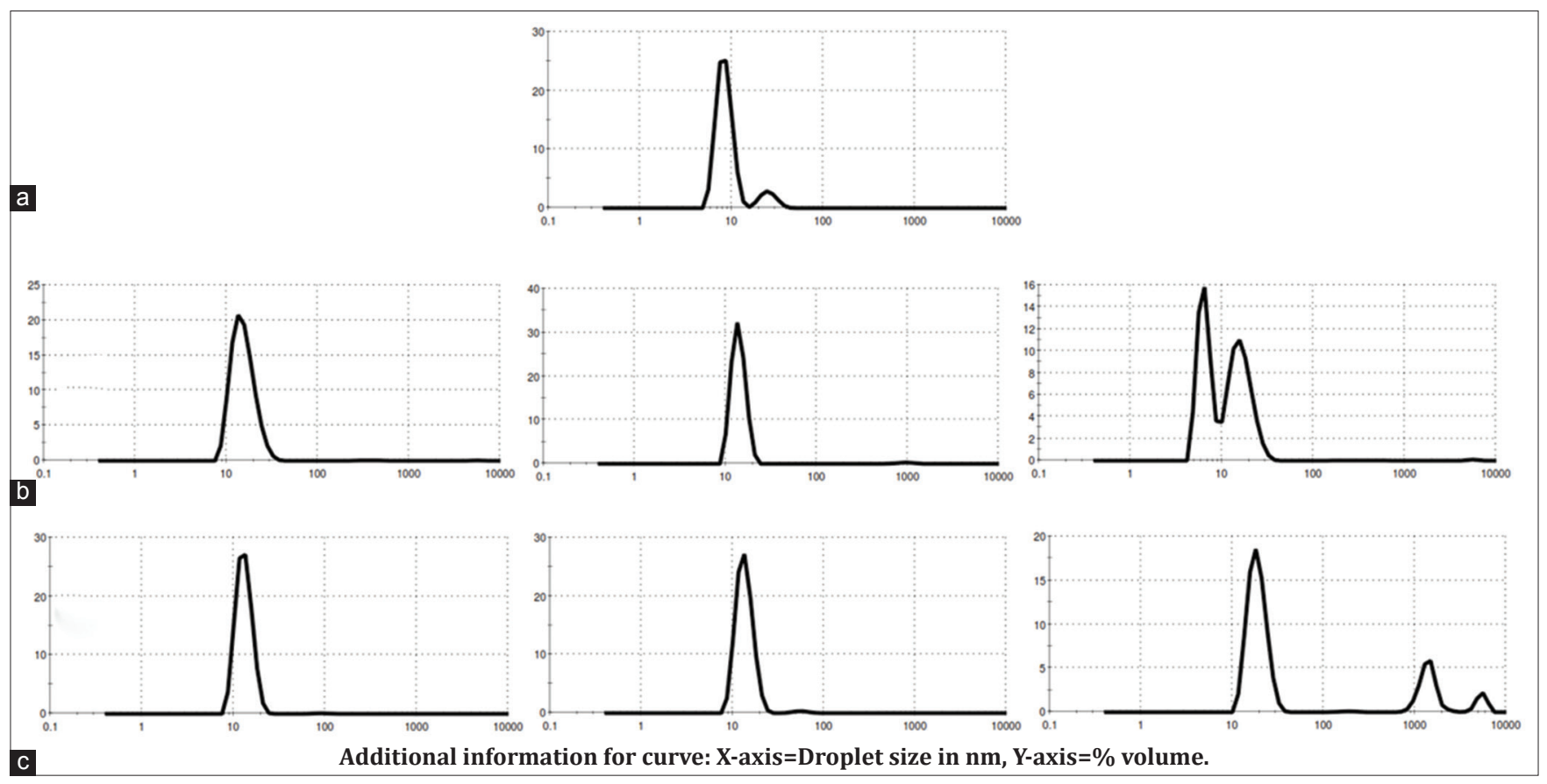

Fig. 5b: Droplet size distribution curves of microemulsion formula A2 (22.5\% Tween 80$)$ stored at low temperature (left), room temperature (middle), and high temperature (right), measured at week 0 (a), week 8 (b), and week 12 (c)



Fig. 5c: Droplet size distribution curves of microemulsion formula A3 (25\% Tween 80) stored at low temperature (left), room temperature (middle), and high temperature (right), measured at week 0 (a), week 8 (b), and week 12 (c)

\section{Physical stability of $\mathrm{W} / 0 / \mathrm{W}$ multiple emulsions}

All formulas showed stable and homogeneous organoleptic properties. Observations during stability tests showed that all $\mathrm{W} / \mathrm{O} / \mathrm{W}$ multiple emulsions appeared stable for 12 weeks; there were no changes in color or smell and no phase separation.

Changes in the $\mathrm{pH}$ of $\mathrm{W} / \mathrm{O} / \mathrm{W}$ multiple emulsions after 12 weeks were insignificant. Based on Fig. 7, the pH values of the three formulas ranged from 2.52 to 2.93; the curves show a relatively stable but insignificant increase in $\mathrm{pH}$.
The mean droplet sizes of the multiple emulsions were measured with an optical microscope equipped with a scale. The total magnification used for observation was $\times 1000$. Fig. 8 shows that the changes in both the inner and outer droplet sizes of the multiple emulsions were relatively small. The changes in the droplet sizes of formulas B1 and B2, for both the inner and outer droplets, were relatively small. The sizes of the internal droplets of formulas B1 and B2 ranged from 0.119 to $0.234 \mu \mathrm{m}$, while formula B3 had a smaller inner droplet size of approximately $0.099-0.210 \mu \mathrm{m}$. 


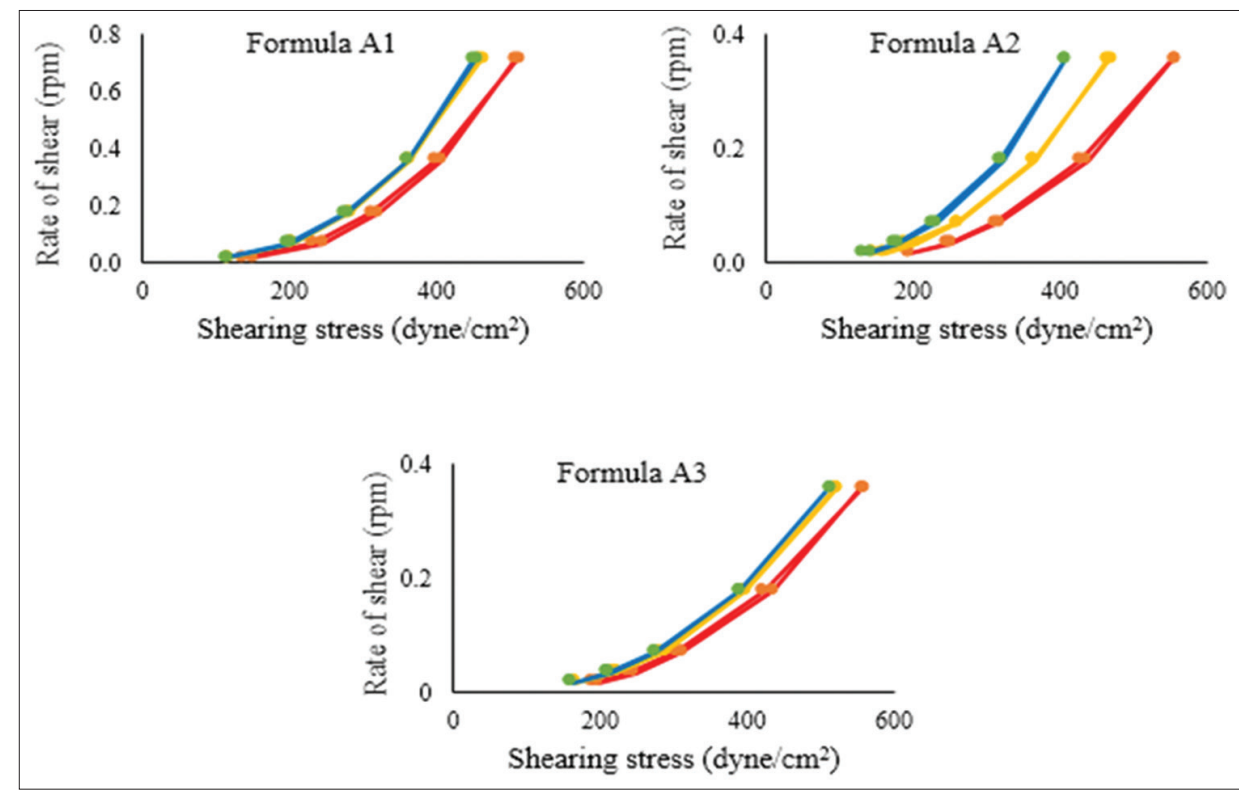

Fig. 6: Rheograms of microemulsions at week 0 (red line), week 4 (yellow line), and week 8 (blue line)

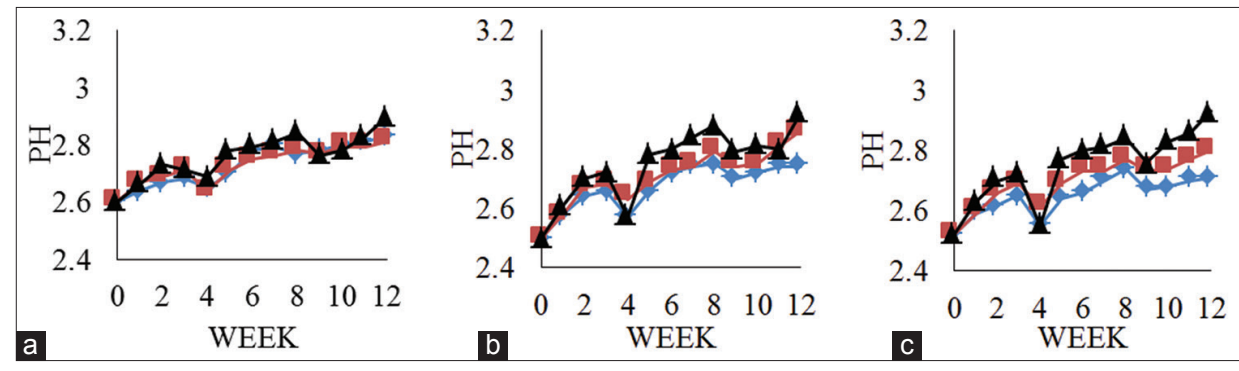

Fig. 7: pH measurements of W/O/W multiple emulsion formulas A1 (a), A2 (b), and A3 (c) at low temperature (blue line), room temperature (orange line), and high temperature (black line)
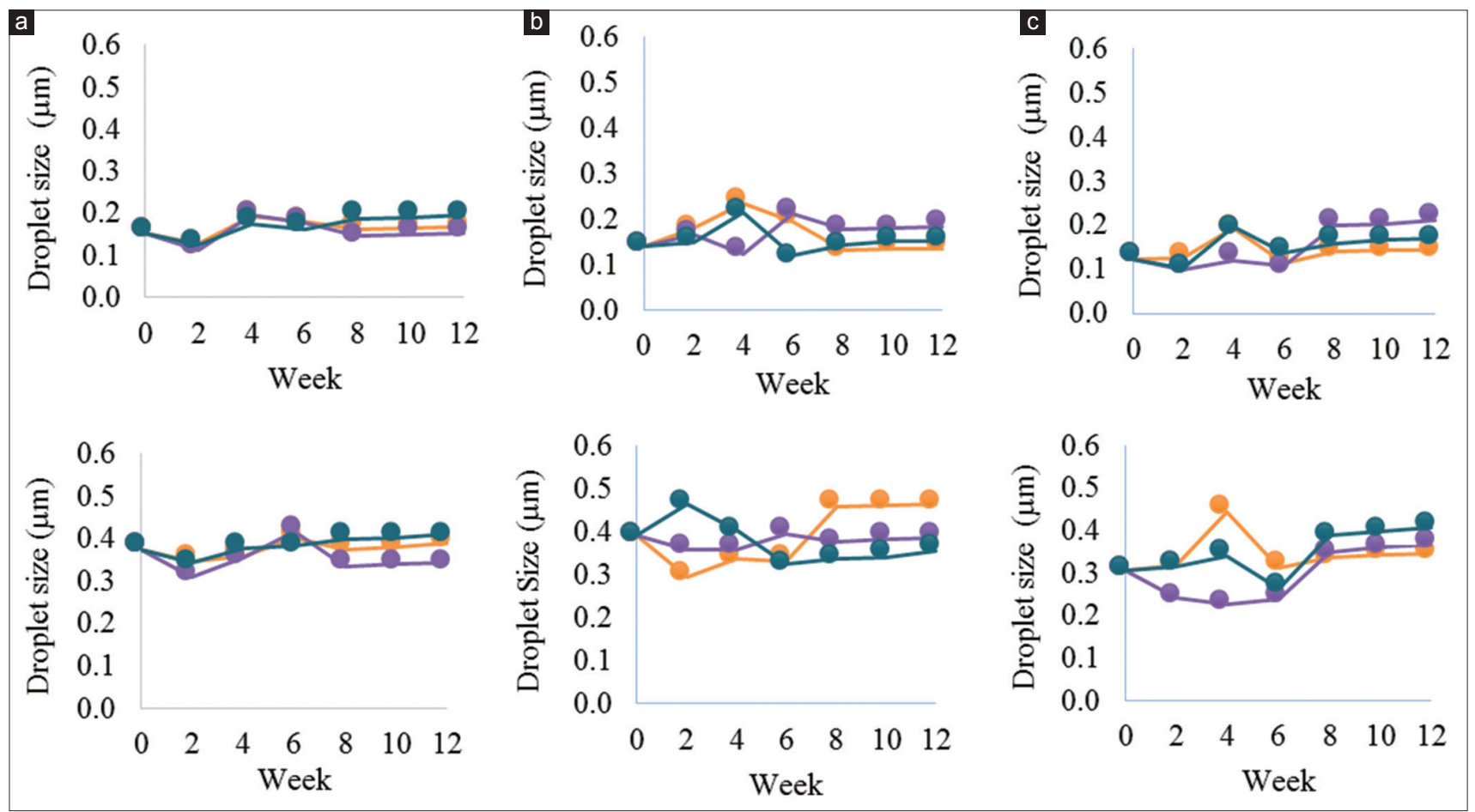

Fig. 8: Measurement of the mean inner droplet size (top) and the mean outer droplet size (bottom) of multiple emulsion formulas B1 (a), B2 (b), and B3 (c) after 12 weeks at low temperature (yellow line), room temperature (black line), and high temperature (green line) 

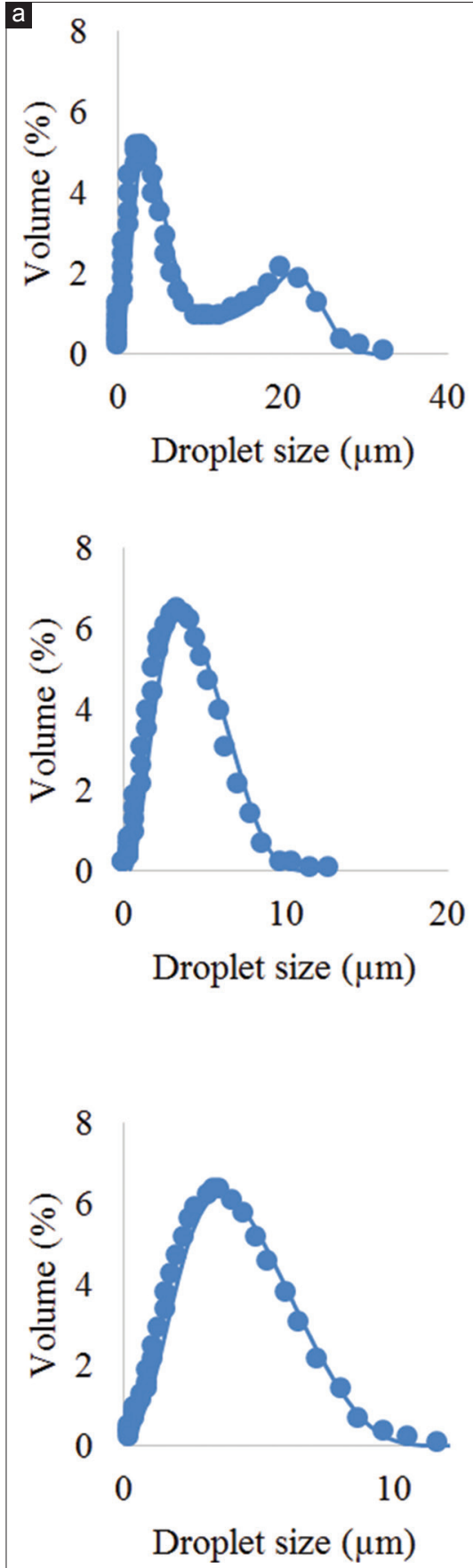
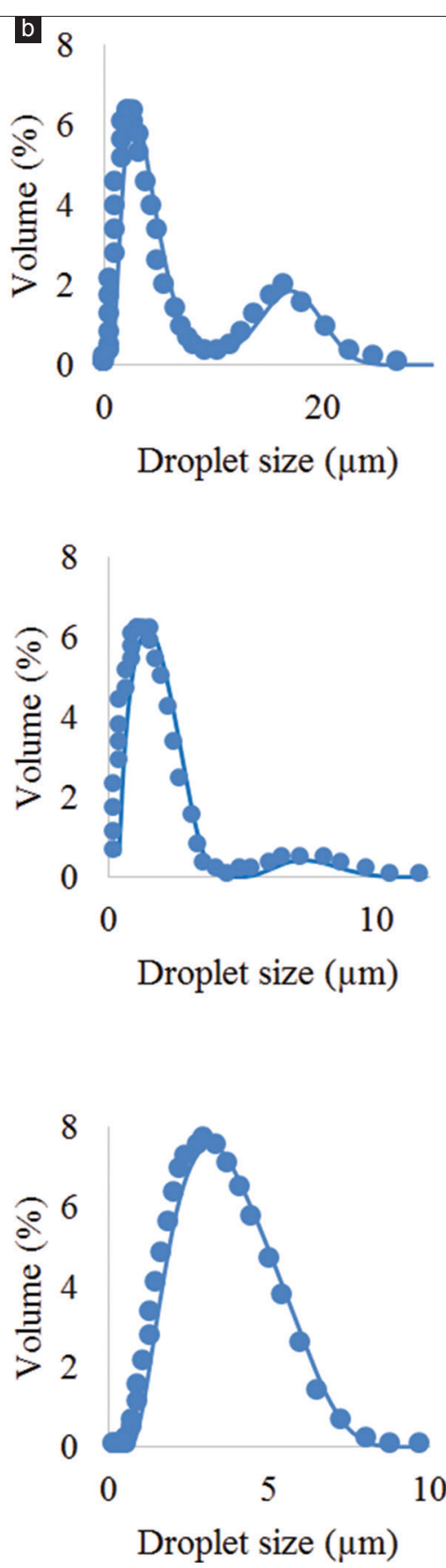
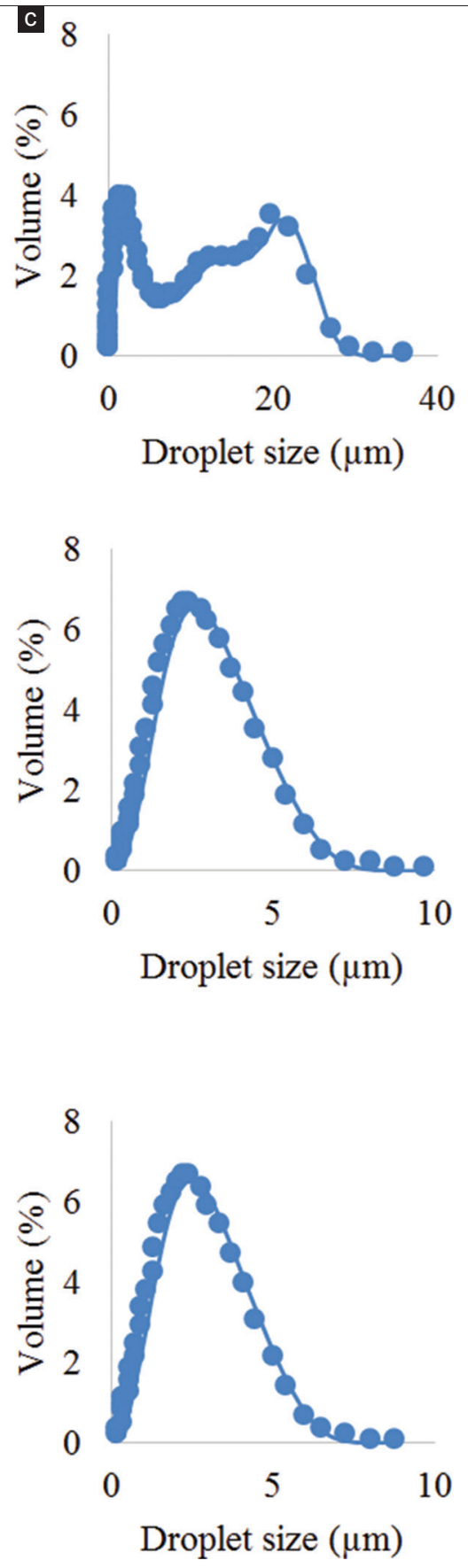

Fig. 9: Droplet size distribution curves of multiple emulsion formulas B1 (a), B2 (b), and B3 (c) stored at low temperature (top), room temperature (middle), and high temperature (bottom), measured at week 6

The multiple emulsion droplet sizes were also measured using a PSA to compare the results with the microscopic measurements. Measurements were taken at weeks 6 and 12 for each formula stored at three different temperatures, low $\left(4 \pm 2^{\circ} \mathrm{C}\right)$, room $\left(28 \pm 2^{\circ} \mathrm{C}\right)$, and high $\left(40 \pm 2^{\circ} \mathrm{C}\right)$ temperatures. As shown in Fig. 9, the particle size distribution curves for the multiple emulsions stored at low temperature showed larger and inhomogeneous droplets, while those stored at room temperature showed relatively homogeneous droplets. The multiple emulsions stored at high temperature showed uniform droplet size distributions.

Fig. 10 shows the flow properties of the multiple emulsions at 0,4 , and 8 weeks. The viscosities of multiple emulsion formulas B1, B2, and B3 at week 0 were 2480,2720 , and $2240 \mathrm{cps}$, and those at week 4 were 2280,2440 , and 1720 cps, respectively. At week 8 , the viscosities were 2240, 2400, and $2000 \mathrm{cps}$, respectively. Based on the viscosity measurements, the three formulas had the same pseudoplastic thixotropic flow properties during 8 weeks of storage, but formula B3 showed pseudoplastic thixotropic properties only up to week 4 .

During the cycling test, none of the multiple emulsion formulas changed color on removal from storage temperatures of $4 \pm 2^{\circ} \mathrm{C}$ or $40 \pm 2^{\circ} \mathrm{C}$. Organoleptic observations of the multiple emulsions indicate that the color of the formula remained unchanged based on color standard Pantone PMS 607. Microscopic observations showed that there were no crystals in the microemulsions.

\section{DISCUSSION}

\section{Microemulsions}

This research aimed to prepare microemulsions with $\beta$-arbutin, sodium ascorbyl phosphate, and lactic acid with isopropyl myristate 


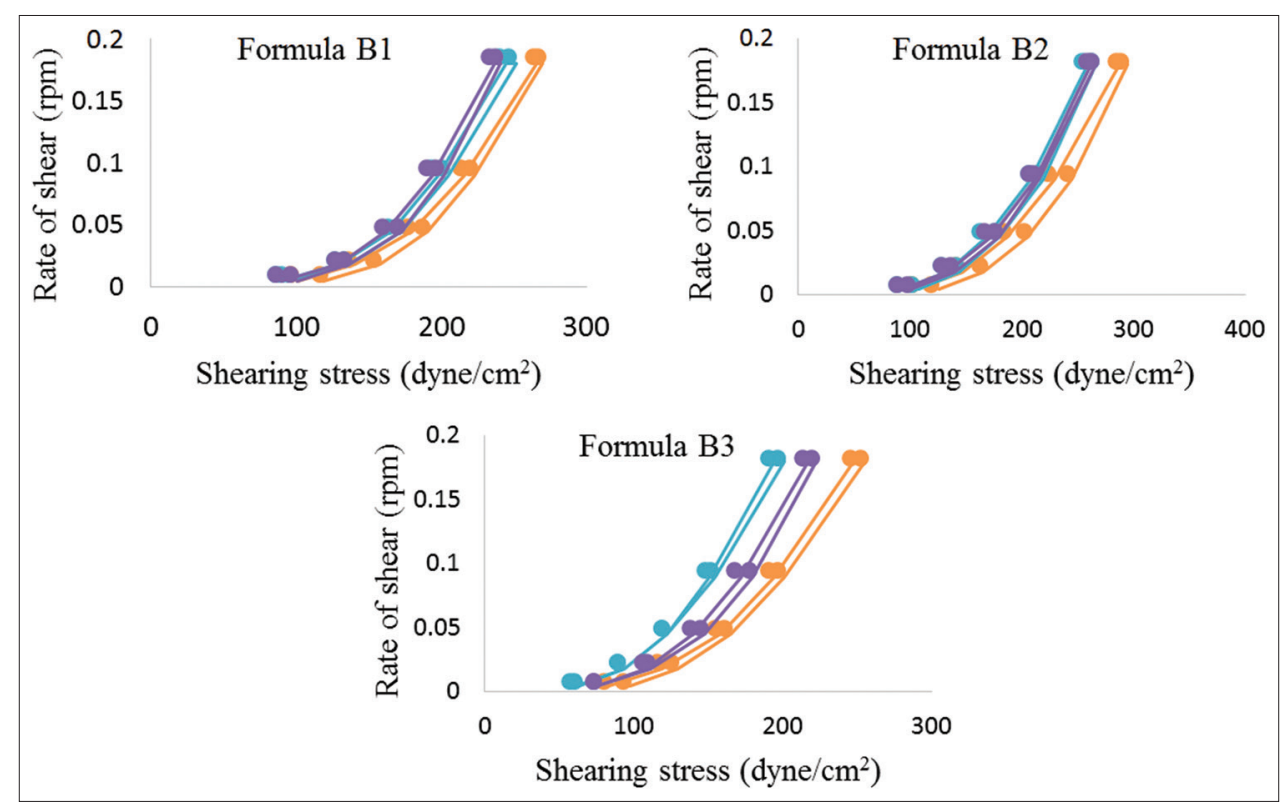

Fig. 10: Rheograms of multiple emulsions at week 0 (green line), week 4 (blue line), and week 8 (yellow line)

as the oil phase and tocotrienol as an antioxidant. To obtain a good and stable formula, three formulas with different concentrations of Tween $80(20 \%, 22.5 \%$, and $25 \%)$ were produced. The surfactant in the microemulsions lowered the interfacial tension between the oil (isopropyl myristate) and water. Microemulsions may also contain a cosurfactant, which generally contains aliphatic alcohols, for example, $96 \%$ ethanol. The surfactant and cosurfactant spontaneously form a solution on rapid stirring to produce small droplets and a very low interfacial tension of approximately $10^{-3} \mathrm{mN} / \mathrm{m}[14,18]$.

The temperatures of the water and oil phases also influence the formation of a microemulsion; as the temperature increases, the viscosity of the oil phase decreases (more aqueous), and the interfacial tension of oil and water decreases and facilitates the formation of emulsions [19]. Dwarakanath et al. added a stabilizer (xanthan gum) after forming an emulsion to increase viscosity and increase the force exerted by the flow, thus preventing instability in the interfacial layer of the microemulsion droplets [20].

The microemulsions produced in this study were aqueous liquids that were odorless and homogeneous. The microemulsion with the highest surfactant concentration showed the highest transparency. During the physical stability test, the color change was insignificant. The microemulsions stored at three different temperatures for 12 weeks did not become rancid. BHT as an antioxidant in a microemulsion can prevent oxidation of the oil phase and prevent rancidity. Among the three formulas, that with the best characteristics as a microemulsion was formula $\mathrm{A} 3$, which contained $25 \%$ Tween 80 and was transparent.

The $\mathrm{pH}$ of the microemulsion was too acidic and thus not ideal, because adjustment with sodium hydroxide was not performed. Polyester compounds such as Tween 80 and Span 80 are prone to hydrolysis with strong bases such as sodium hydroxide. During stability study, the $\mathrm{pH}$ of the microemulsion was expected to increase due to the release of sodium ions from sodium ascorbyl phosphate, which reacts with water to form sodium hydroxide and increase the $\mathrm{pH}$.

Droplet size measurement using a PSA at week 0 showed that the microemulsion with the highest Tween 80 concentration had the highest globule size. The droplet size of the microemulsion was not only influenced by the amount of surfactant; other factors, such as stirring speed and stability factors, such as hydrolysis of ester surfactants, also affected the probability that small droplets would coalesce and form larger droplets. During storage at low and room temperatures, the droplet size distribution curves at weeks 8 and 12 indicated that there was no coalescence between droplets. However, during storage at high temperatures, the microemulsion globules tended to form larger globules because of differences in the distributions at weeks 0 , 8 , and 12 .

The viscosities of the microemulsions were relatively low due to the low concentration of xanthan gum as a thickening agent, which was $0.3 \%$. Formula A1 had the lowest viscosity compared to the other formulas due to its Tween 80 concentration being low (20\%). A higher surfactant concentration results in higher viscosity because this produces smaller droplets. During 12 weeks of storage, the viscosity of the microemulsions decreased. This was due to an increase in the droplet size (coalescence) and the effects of changes in the polymer structure during storage. During storage, microemulsion droplets tend to aggregate and produce larger droplets, decreasing the viscosity. All the microemulsion formulas showed pseudoplastic flow properties during 8 weeks of storage. According to Kogan and Garti, a microemulsion has low viscosity and Newtonian flow properties because of its small droplet size [21].

\section{$\mathrm{W} / \mathrm{O} / \mathrm{W}$ multiple emulsions}

A key factor that affects the stability of a multiple emulsion is a twolayer interface that is thermodynamically unstable, so two different emulsifiers are needed to stabilize these layers. Emulsifiers with low hydrophilic/lipophilic balance (HLB) values are required at the interface layer of a W/O primary emulsion, while an emulsifier with a high HLB value is needed at the interface layer of a W/O/W multiple emulsion [16]. Span 80 with an HLB value of 4.3 and Tween 80 with an HLB value of 15 were used in this study. A water phase is used for a primary emulsion, namely, an internal water phase in the form of a $0.2 \mathrm{M}$ sodium chloride solution. Sodium chloride is used to maintain the osmotic pressure between the internal and external water phases and balance the Laplace pressure [22]. To stabilize each droplet of a multiple emulsion, xanthan gum is added. According to Ozer et al., adding xanthan gum can improve the internal globule adsorption of a multiple emulsion, influence the droplet size, and affect the comfort of the formula when it is applied to the skin [17].

The W/O/W multiple emulsions had the same physical characteristics; namely, they were white-yellow (Pantone PMS 607), odorless, less viscous, homogeneous, and exhibited no visible phase separation and no color change during 12 weeks' storage. The $\mathrm{pH}$ of the multiple emulsions was too acidic for skin due to the presence of lactic acid, which has a low $\mathrm{pH}$. 
On microscopic observation, the emulsion droplets of formula B3 were not clearly visible because a high concentration of Span 80 produced droplets that were too small. During storage, there were slight changes in both the inner and outer droplets of the multiple emulsion. Changes in droplet sizes occur during storage due to a coalescence mechanism between the internal and external water phases. An increase in the droplet size can reduce the Laplace pressure, inducing diffusion of water from the external water phase to the internal water phase [23]. Based on calculations using a PSA and microscopic observation, it can be concluded that the multiple emulsions were unstable when stored at low temperatures because the droplets in the three formulas tended to coalesce.

The viscosities of the $\mathrm{W} / \mathrm{O} / \mathrm{W}$ multiple emulsions were greater than those of the microemulsions due to the influence of the xanthan gum concentration, which was higher in the multiple emulsions $(0.7 \%)$ than in the microemulsions $(0.3 \%)$. Changing the amount of Span 80 did not significantly influence the viscosity. Technically, the speed and duration of stirring when adding xanthan also affected the viscosity. The viscosity of multiple emulsions showed an insignificant decrease after 4 weeks' storage, except for formula B3, whose viscosity increased at week 8. Based on viscosity measurements, all the multiple emulsion formulas showed pseudoplastic thixotropic flow properties during 12 weeks' storage. However, formula B3 showed pseudoplastic flow properties only up to week 4 . This is possible because the higher Span 80 concentration produced smaller droplets, which increased the area of the interfacial layer and thus the contact between internal and external water droplets, resulting in an increased droplet coalescence rate [24].

\section{CONCLUSION}

The microemulsion formula with $25 \%$ Tween 80 was the most transparent and had a droplet size of $15.50 \mathrm{~nm}$. W/O/W multiple emulsions with $2 \%$ and $2.5 \%$ Span 80 showed droplets within droplets, which dispersed in a continuous phase with inner droplet sizes of 0.153 and $0.140 \mu \mathrm{m}$ and outer droplet sizes of 0.373 and $0.390 \mu \mathrm{m}$. All microemulsion formulas were stable at low $\left(4 \pm 2^{\circ} \mathrm{C}\right)$ and room $\left(28 \pm 2^{\circ} \mathrm{C}\right)$ temperatures. W/O/W multiple emulsions with $2 \%$ and $2.5 \%$ Span 80 were stable at room $\left(28 \pm 2^{\circ} \mathrm{C}\right)$ and high $\left(40 \pm 2^{\circ} \mathrm{C}\right)$ temperatures.

\section{ACKNOWLEDGMENT}

The authors gratefully acknowledge Universitas Indonesia for support and a PITTA research grant 2019

\section{CONFLICTS OF INTEREST}

The authors declare that they have no conflicts of interest.

\section{REFERENCES}

1. Goon P, Allison C. Whose debt? Globalization and White-facing in Asia. Intersections: Gender, History and Culture in the Asian Context. Available from: http://www.sshe.murdoch.edu.au/intersections/issue9/ gooncraven.html.
2. Eric P, Hyun JM, Russel W, Junko K, Shalini B. Skin lightening and beauty in four Asian cultures naacr. Assoc Consum Res 2008;35:273.

3. Draelos ZD, Thaman LA. Cosmetic Formulation of Skin Care Products. New York: Taylor and Francis Group; 2006. p. 205-8.

4. Degen HG. Scientific committee on consumer products opinion on $\beta$-arbutin. Regul Toxicol Pharmacol 2015;73:866-77.

5. Parvez S, Kang M, Chung HS, Cho C, Hong MC, Shin MK, et al. Survey and mechanism of skin depigmenting and lightening agents. Phytother Res 2006;20:921-34.

6. Chakraborty AK, Funasaka Y, Komoto M, Ichihashi M. Effect of arbutin on melanogenic proteins in human melanocytes. Pigment Cell Res 1998;11:206-12.

7. Elsner P, Maibach HI. Cosmeuticals and Active Cosmetics: Drug Versus Cosmetics. New York: Taylor and Francis Group; 2005. p. 272-3.

8. Stiller MJ, Bartolone J, Stern R, Smith S, Kollias N, Gillies R, et al. Topical $8 \%$ glycolic acid and $8 \%$ L-lactic acid creams for the treatment of photodamaged skin. A double-blind vehicle-controlled clinical trial. Arch Dermatol 1996;132:631-6.

9. Telang PS. Vitamin C in dermatology. Indian Dermatol Online J 2013;4:143-6

10. Swarbrick J. Encyclopedia of Pharmaceutical Technology. $3^{\text {rd }}$ ed. USA: Informa Health Care; 2007. p. 1561-4.

11. Peira E, Carlotti ME, Cavalli R, Trotta M. Azelaic acid sodium salt in the formulation of microemulsions for topical applications. J Drug Deliv Sci Tech 2006;16:375-9.

12. Kumar R, Kumar MS, Mahadevan N. Multiple emulsions: A review. Int J Recent Adv Pharm Res 2012;2:9-19.

13. Rahul S, Shweta K, Shailendra S, Swarnlata S. Formulation and characterization of herbal cosmetic multiple emulsion. J Res Educ Indian Med 2011;17:23-7.

14. Li P, Ghosh A, Wagner RF, Krill S, Joshi YM, Serajuddin AT. Effect of combined use of nonionic surfactant on formation of oil-in-water microemulsions. Int J Pharm 2005;288:27-34.

15. Spiclin P, Gasperlin M, Kmetec V. Stability of ascorbyl palmitate in topical microemulsions. Int J Pharm 2001;222:271-9.

16. Schmidts T, Dobler D, Guldan AC, Paulus N, Runkel F. Multiple $\mathrm{W} / \mathrm{O} / \mathrm{W}$ emulsions-using the required HLB for emulsifier evaluation. Colloids Surf A 2010;372:48-54.

17. Ozer O, Muguet V, Roy E, Grossiord JL, Seiller M. Stability study of $\mathrm{W} / \mathrm{O} / \mathrm{W}$ viscosified multiple emulsions. Drug Dev Ind Pharm 2000;26:1185-9.

18. Israelachvili JN, Mitchell DJ, Ninham BW. Theory of self-assembly of hydrocarbon amphiphiles into micelles and bilayers. J Chem Soc Faraday Trans II 1976;72:1525-68.

19. Al-Mulla A, Gupta R. Droplet coalescence in shear flow of model emulsions. Rheol Acta 2000;39:20-5.

20. Dwarakanath V, Kostarelos K, Pope GA, Shotts D, Wade WH. Anionic surfactant remediation of soil columns contaminated by nonaqueous phase liquids. J Contam Hydrol 1999;38:465-88.

21. Kogan A, Garti N. Microemulsions as transdermal drug delivery vehicles. Adv Colloid Interface Sci 2006;123-126:369-85.

22. Mezzenga R, Folmer BM, Hughes E. Design of double emulsions by osmotic pressure tailoring. Langmuir 2004;20:3574-82.

23. Jiao J, Rhodes DG, Burgess DJ. Multiple emulsion stability: Pressure balance and interfacial film strength. J Colloid Interface Sci 2002;250:444-50.

24. Schuch A, Deiters P, Henne J, Köhler K, Schuchmann HP. Production of W/O/W (water-in-oil-in-water) multiple emulsions: Droplet breakup and release of water. J Colloid Interface Sci 2013;402:157-64. 